\title{
AN ALTERNATE END DESIGN FOR SSC DIPOLES*
}

\author{
C. Peters, S. Caspi, and C. Taylor
}

\author{
Accelerator \& Fusion Research Division \\ Lawrence Berkeley Laboratory \\ 1 Cyclotron Road \\ Berkeley, CA 94720
}

February 1989

*This work is supported by the Office of Energy Research, Office of High Energy and Nuclear Physics, High Energy Physics Division, Dept. of Energy under Contract No. DEAC03-76SFOOO98. 


\title{
AN ALTERNATE END DESIGN FOR SSC DIPOLES*
}

\author{
Craig Peters, Shlomo Caspi, and Clyde Taylor \\ Lawrence Berkeley Laboratory \\ 1 Cyclotron Road \\ Berkeley, CA 94720
}

\begin{abstract}
Experience in the SSC dipole program has shown that fabrication of cylindrical coil ends is difficult. Cable stiffness requires large forces to maintain the proper position of the conductors in the end during winding. After winding, the coil ends remain distorted and significant motion of the end conductors is required to force the coil end into the molding cavity. Local mechanical stresses are high during this process and extra pieces of insulation are required to prevent tum-toturn shorts from developing during the winding and molding steps. Prior to assembly the coil end is compressed in a mold cavity and injected with a filler material to correct surface irregularities and fill voids in the end.

LBL has developed an alternate design which permits the conductors to be wound over the ends using minimal force and technician coersion. The conductors are placed on a conical surface where the largest diameter over the outer layer conductors is $10 \mathrm{~cm}$. No coil end spaces or insulation pieces between turns are required. The conductor geometry was analytically optimized to meet SSC multipole requirements for the ends. The first $1-\mathrm{m}$ dipole utilizing this end geometry has been constructed and successfully tested. Design and construction data are presented. Also, model test results, including training and multipole measurements of the end, are given.
\end{abstract}

\section{INTRODUCTION}

The forming of straight dipole coil ends in SSC prototype models has historically proven difficult. Large forces are required to position the conductor during coil winding and during subsequent insertion of the wound coil into the moiding cavity. This is due to the resistance of the superconducting cable to being formed to the small radii required in the ends of small aperture straight ended magnets. The inherent stiffness of the cable is increased by the glass tape wrap used on the cable over the Kapton insulating wrap. The cable insulation is scuffed and traumatized during winding and molding resulting in occasional turn to turn shorts in the ends of the formed coils that sometimes appear or later during coil assembly. At BNL and LBL the occurrence of these shorts has been reduced but not eliminated by installing extra insulation and fiberglass strips between turns in the ends during coil winding.

*This work was supported by the Director, Office of Energy Research, Office of High Energy and Nuclear Physics, High Energy Physics Division, U.S. Department of Energy, under Contract No. DE-AC03-76SF00098. 
Another problem with straight ends is the tendency for the molded coil ends to lose their shape following removal from the molding fixture due to high residual stresses in the wire. As the shaped end tries to flatten out, the insulation is further damaged. Also assembly of the misshapened end is made more difficult.

Two fixes to the problems of straight ends have been tried. At BNL, the coil ends are filled or potted as the final step in the molding process. This eliminates voids and helps the end to maintain its shape; the filling material allows the conductors in the end to be well clamped and supported after assembly. However, the basic difficulty in winding and molding still remains - that is turn to turn shorts can only be prevented by operator skill and the use of insulating strips and separators between turns.

A second fix has been recently tried at LBL and at FNAL. This is the constant perimeter approach which attempts to reduce cable stresses by tilting the cable in the end so that the inner and outer edge perimeter lengths are the same. The tilting of the conductor in the pole region shortens the cable radial height and allows introduction of a thin tapered cone to both support the winding during assembly and give it a precise cylindrical outside diameter. Introduction of this approach has only slightly improved the windability of straight coil ends. This is partly because the existing straight end uses a semi-constant perimeter geometry. Also because of the small bending radius, there are still significant stresses in the cable even with the constant perimeter geometry. At least three carefully shaped end spacers are required in each end of the inner coils to place the turns close to their constant perimeter shape. It is likely that separators and/or separate insulating strips between turns will be continued to be required for electrical reliability.

At LBL we have designed and built a dipole model with a new end geometry in which the problems of the straight end are for the most part eliminated. The magnetic and mechanical designs have been done consistently to produce an end which is easy to wind and assemble, requires relatively few individual pieces, and whose magnetic multipoles stay within the SSC specifications.

\section{FLARED END DESIGN}

The alternate design proposed at LBL is referred to as the flared end design. The primary goal of this design was to produce a winding that was first of all more electrically rugged and reliable than the present designs and at the same time meet the SSC end multipole requirements. The secondary goal was to produce a more manufacturable end, requiring less technician time and skill to wind and mold.

Since the problems of electrical reliability and winding difficulty for straight SSC dipole ends result primarily from high forces required to bend the conductor around the small radii inherent in small bore dipole magnets, the approach was to increase the bending radii of the end conductors as much as possible.

The natural way to increase conductor radii is to wind the end conductors on a conical surface. The geometry chosen is a simple conical surface in which the cone axis is tilted slightly with respect to the dipole axis as shown in Figure 1. (We observed that a coil wound on a nontilted cone surface drooped toward the coil axis when the coil was removed from its supporting cone.) After experimenting with several shapes, a 19 deg. cone with its axis tilted downward at 5 deg., shown in Figure 1, was chosen as the basic geometry for LBL's flared end. The inner and outer surface of each conductor layer each have this geometry, that is, a 19 deg. cone with its axis tilted dcwnward at $5 \mathrm{deg}$. The four conical surfaces of each half of the dipole have a common axis and are concentric cones. The radial thickness of the space separating the inner coil outer surface and the outer coil inner surface was chosen to be $1.25 \mathrm{~mm}$, enough to provide adequate space to accommodate small variations in overall length that might occur in manufacturing. This separator 
is explained more in the Coil Assembly section below.

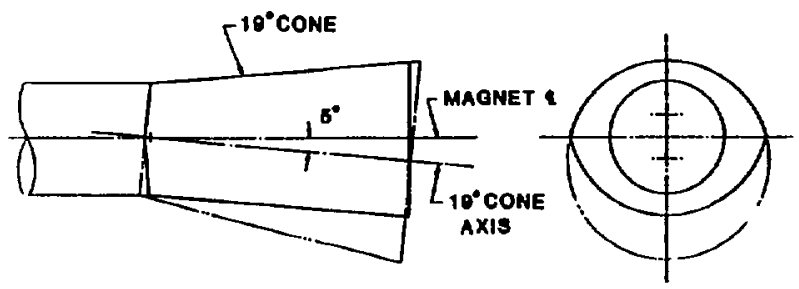

Figure 1 Flared End Geometry

Tooling

The tilted cone geometry results in straightforward procedures for designing tooling. Dimensions were computed using a simple geometry program and verified using 2-D CAD layouts. Machining of the winding cones and molding cavities for the end were done using conventional milling machines and lathes in most cases. Several pieces were maciined using 3axis CNC machines because of the simplicity of programming the shapes involved. A flared end coil molding cavity is shown in Figure 2.

\section{Magnetic Optimization}

With the conical surfaces now chosen the optimum conductor placement was selected that would produce magnetic multipoles within the SSC end multipole requirements. Two constraints were impused for mechanical reasons; rule one: the conductor was permitted to tilt a maximum of 10 deg. from an orientation normal or perpendicular to the conical surface. The purpose here was to maintain adequate thickness of each coil end to eliminate complications that would arise from radial thickness deficits. Rule two was to have no separate coil blocks in the ends, so that the ends have no spacers and the conductors pass over the pole as one block. This was to keep the design simple with a minimum number of parts to fabricate and install during coil winding.

Programming of the end geometry is described in Ref. 1. A "wire frame" for the purpose of optimizing the magnetic field geometry was used where each turn is represented by one wire as shown in Figure 3. The computation assumes the current is concentrated at the wire. Ramp and return sections of the end are defined as in Figure 4. The computations assume the cable crosssection dimensions in the end remain the same as in the straight section, i.e. no distortion of the cable cross-section. The "teardrop" determines the position of the first conductor turn. The two parameters that could be varied in the computations to adjust multipoles were the length and width of the teardrop. Rule two above necessitates that the straight section copper wedges be terminated at the start of the end and feathering wedges be used in the ramp section of the end to gather the four straight section conductor blocks into one block for the return trip over the pole. Rule one above necessitates a wedge at the midplane of the ramp section in order to keep the conductors in this section standing nearly normal to the conical surfaces. 


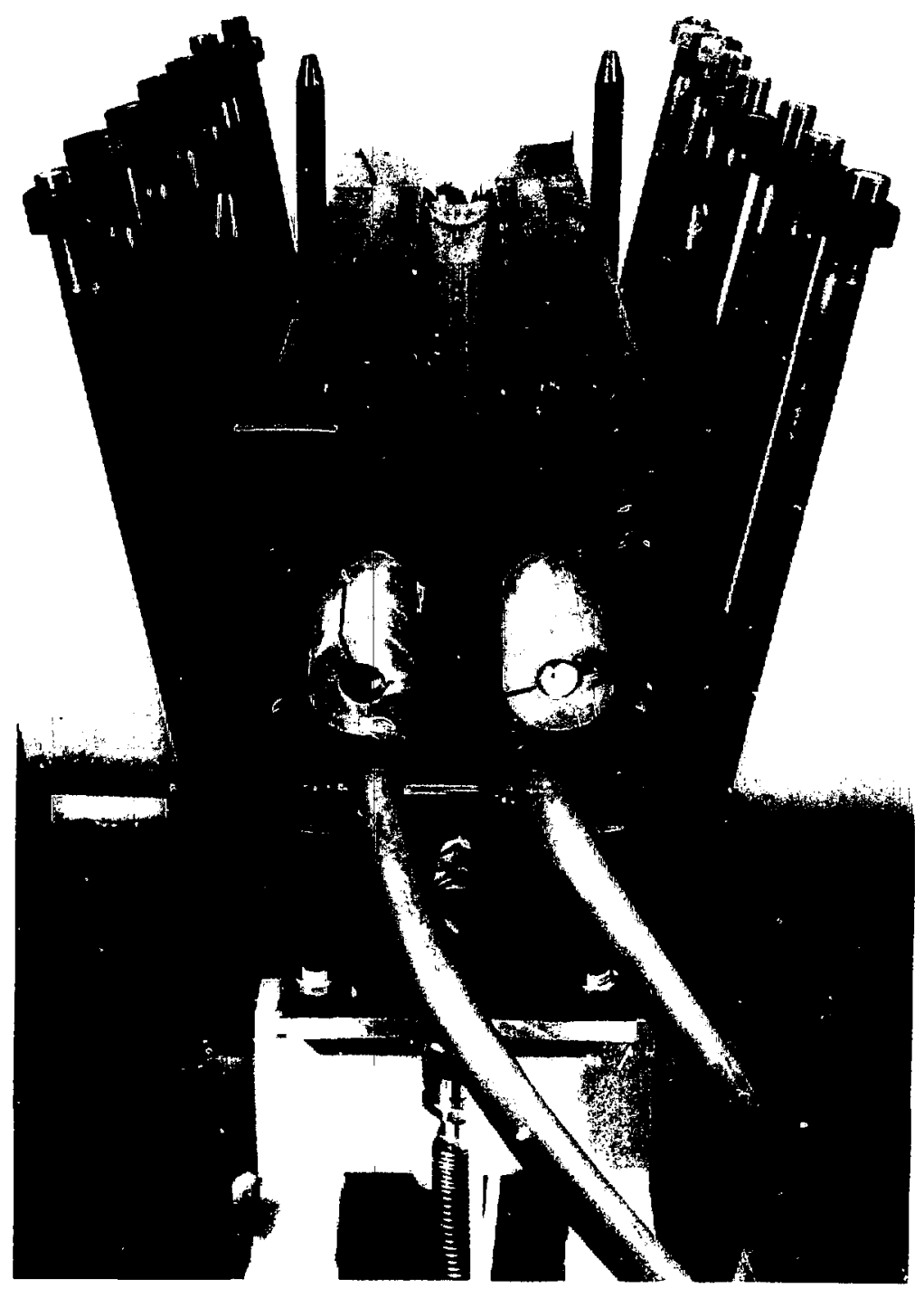

Figure 2 Flared End Molding Cavity 


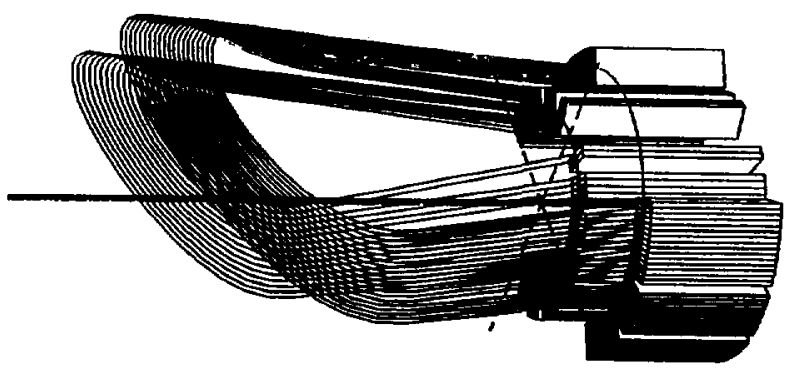

Figure 3 Wire Frame End Geometry

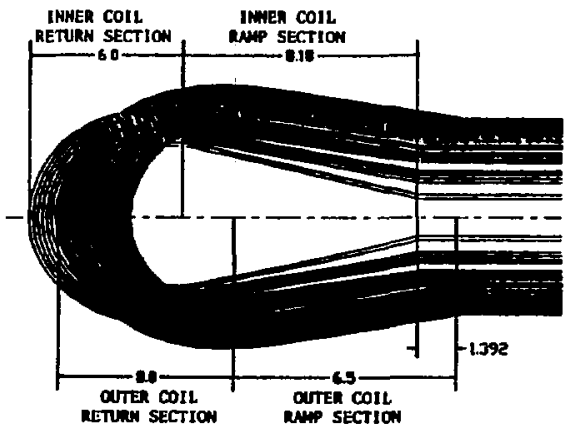

XBL $897-2671$

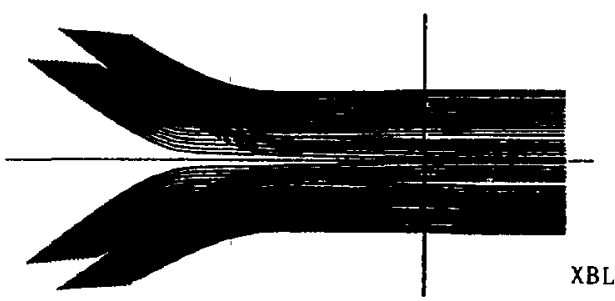

XBL $897-2672$

Figure 4 End Ramp \& Retum Sections

\section{Final End Shapes}

For our first model, the feathering wedges, teardrop, and end shoe were machined from sections of G-10 tube stock (in production, these parts would be injection molded). The basic conical surfaces were machined conventionally on a lathe. The contoured faces that contact the cable were machined using an N.C. controlled three axis milling machine programmed using data from the "geometry" program described above. The final shapes of these end parts was determined assuming the conductor thickness was the same in the end as it was in he straight section.

\section{Coil Winding \& Molding}

Machined aluminum winding cones having the conical external surface tilted at the prescribed 
5 deg., with a cylindrical bore are attached to a cylindrical winding mandrel shown in Figure 5 . A steel winding pole attached to the mandrel terminates at the leading edge of the winding cone. The machined G-10 teardrop, described above, is accurately fixed on the winding cone using two 0.8 $\mathrm{cm}$ diameter pins. The teardrop inner tip is supported in the axjal direction against the end of the steel winding pole. During winding, the inner coil lead is routed radially inward through the teardrop and winding cone inte the end of the cylindrical winding mandrel, Figure 6.

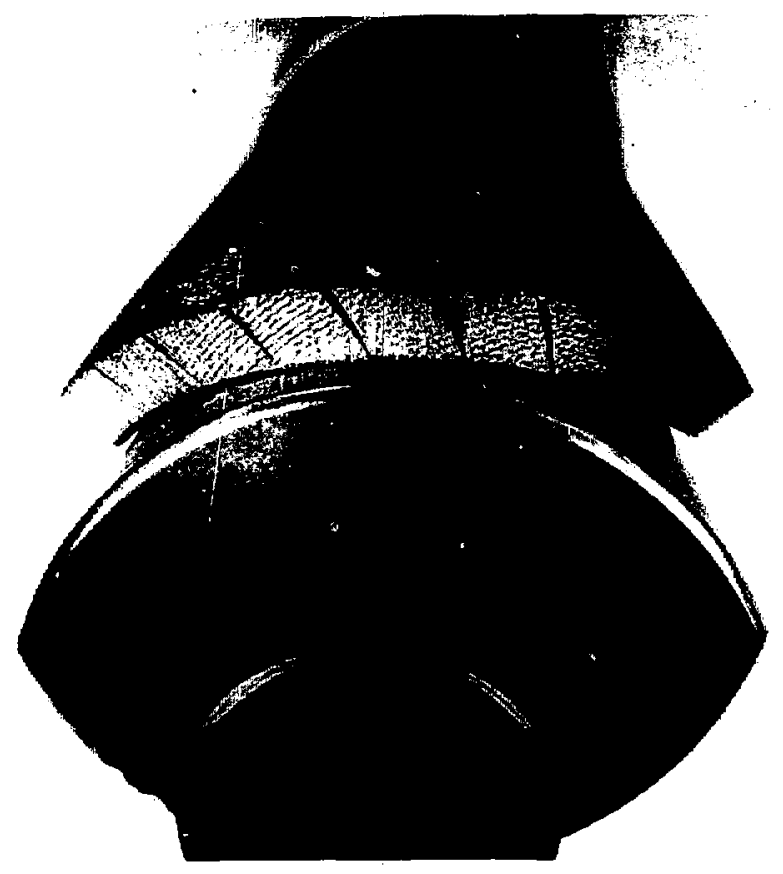

Figure 5 Coil End Winding Cone

CBB 893-1656 


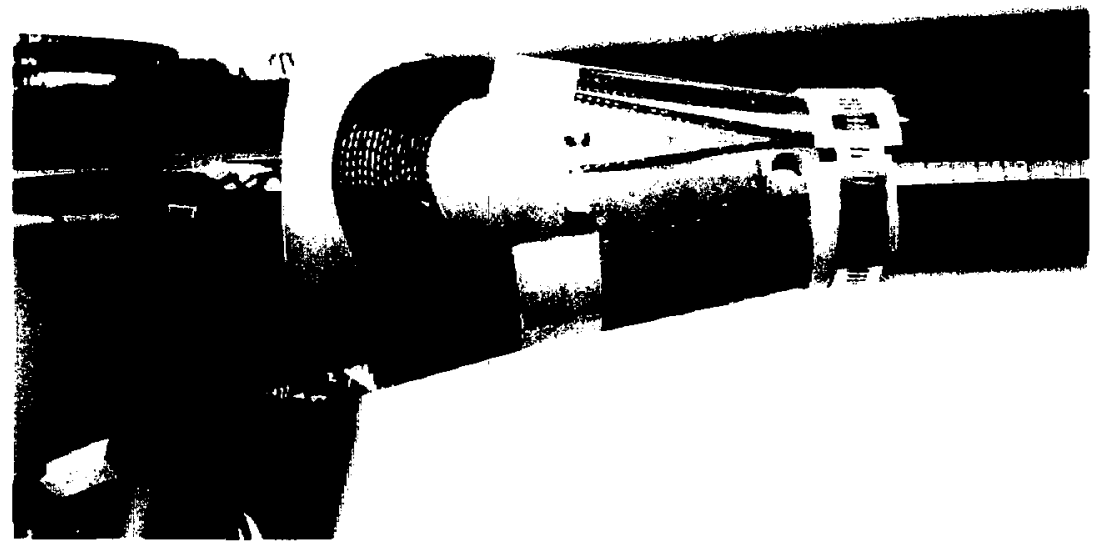

Figure 6 Coil Pole Lead Routing During Molding

XBC $854-3163$

Cable tension is set at $18 \mathrm{~kg}$ during coil winding. As each turn is wound onto the mandrel, a spring loaded clamp, is used to draw the conductor up against the teardrop at the end of the straight section; this creates a "reverse" bend in the cable. It is not necessary that the conductor be held tightly against the teardrop during winding. The effect of leaving "sag" in the conductor at this point is to cause in the area the innermost turns of conductor to tighten firmly against the end of the teardrop as the coil is compressed in the molding fixture. This is a desirable effect in constrast with the tendency in straight ended coils for the conductor to loosen at the end as the coil is compressed in the molding fixture. During winding, a minimal amount of mechanical tapping is used to aid in firmly positioning the conductors at the end. After winding and before insertion into the molding fixture, the conductor conforms to the conical winding surface with a maximum gap under the conductor of only about $2 \mathrm{~mm}$. (for the inner coil). Figure 5 shows a molded inner coil viewed from the end. The ability of the coil end hold its as-wound shape is apparent.

As mentioned above the final shapes of the end parts were determined assuming the conductor thickness would be the same in the end as it is in the straight section. The cable in the ramp section of the end compressed to the same thickness as the cable straight section conductor during the molding step. However, no axial load is applied to the return portion of the end during molding. As a result, the conductor thickness at the end of the return section increases slightly. The end of the molded inner coils were measured and the average conductor thickness at this point was found be larger than the nominal by $17 \%$ (about $0.28 \mathrm{~mm}$ total for 16 turns compared to about $0.45 \mathrm{~mm}$ for straight ended coils. ref. 1 ). 


\section{Coil Assembly}

Figure 7 shows an exploded view of the flared end coil assembly. The two aluminum end cones are positioned and aligned by a fixture at each end of the assembly table. The G-10 teardrops are precisely located on the cones by s.s. assembly pins, Figure 8. At the lead e1.1 the coil lead from the inner turn is routed radially outward through the $\mathbf{G}-10$ teardrop as shown in Figure 8. The end shoe contour was trimmed to fit the final coil end shape. After mounting the coil, teardrops, and end shoes, the coil end is clamped and wrapped with a thin $(0.25 \mathrm{~mm})$ flat braid of Kevlar to hold it in position; this step might be omitted for a production magnet, but is used here as a convenient assembly aid. The entire inner layer including ends is wrapped with teflon sheet to minimize friction between layers. A $1 \mathrm{~mm}$-thick molded end separator is placed over the inner coil end held in and position by the assembly pins in the end cone. The purpose of this separator is to allow adjustment of the relative axial position of the inner and outer coil ends. This is not necessary in $1-\mathrm{m}$ models but in full length $17-\mathrm{m}$ models the coils may have slightly varying lengths after being removed from the molding tooling. If this occurs, it may be accommodated at assembly by using a thinner or thicker separator. If necessary, a $1 \mathrm{~cm}$ relative length change of the inner coil compared to the outer coil in either direction, could be conveniently accommodated by this method.

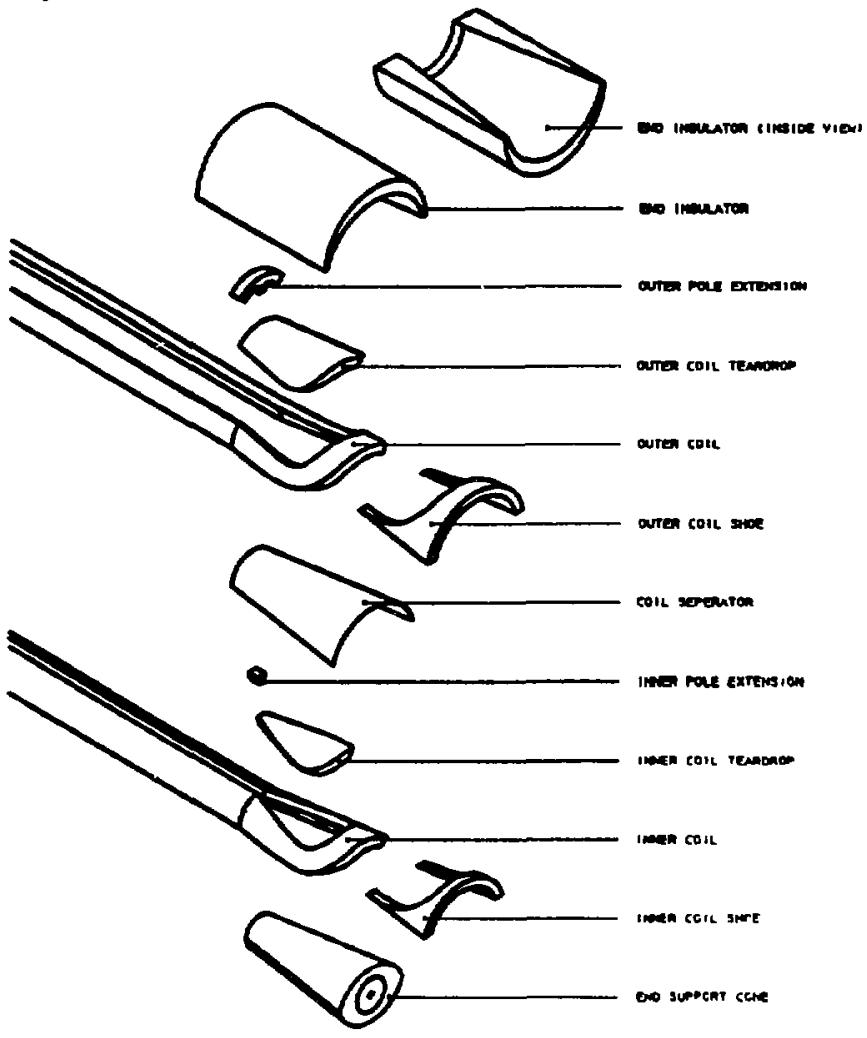

Figure 7 Exploded View of Flared End Coil 


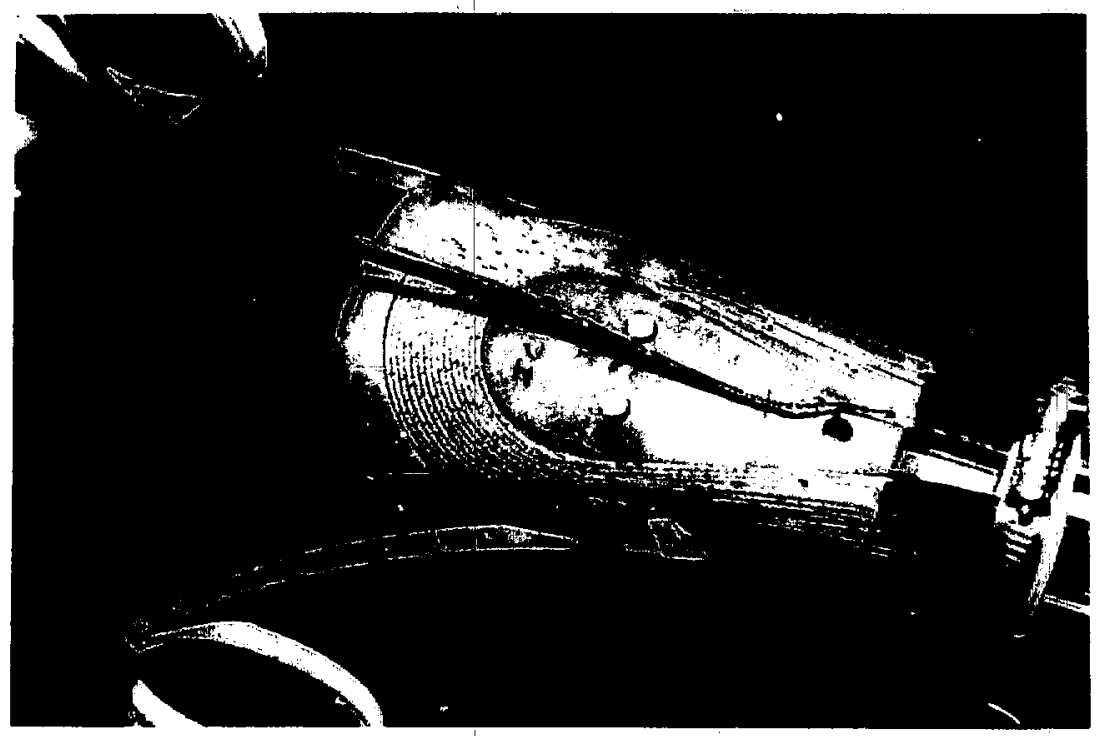

Figure 8 Inner Pole Lead Exiting Coil End

CBB 893-2307

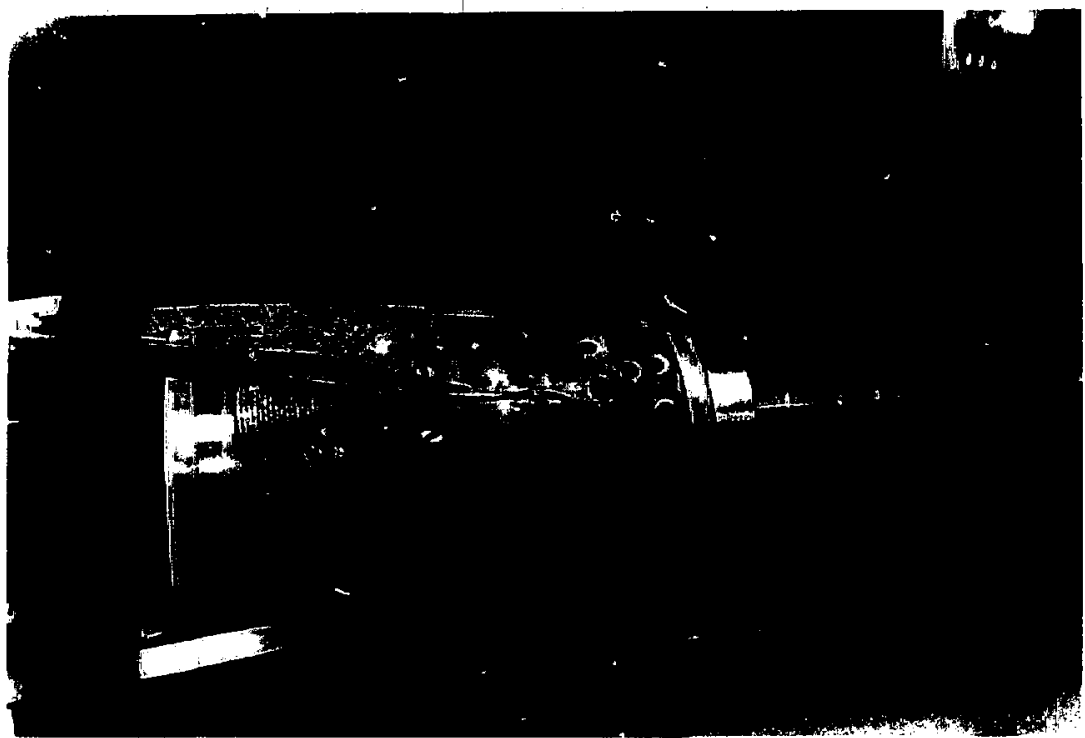

Figure 9 Pole Leads Coming Out of Coil End 
The outer coil is mounted similarly to the inner coil with alignment pins to position the coil end. Both inner and outer coil leads egress from the outer conical surface of the outer coil teardrop, Figure 9. Pole extension blocks, shown in Figures $7 \& 10$, are positioned at the inner end of the coil teardrops. These blocks have the same inner profile as the collars and provide a short "straight" section to lead into the flared end. The G-10 insulator, Figures 7 \& 10, has a short cylindrical section which transitions tc the conical section. The inner surface of this insulator is precisely contoured using a N.C. machining to provide proper positioning and clanping of the coil end as it transitions from the straight to flared section. A second function of this $\mathrm{G}-10$ extension block is to allow the Kapton ground plane insulation to extend about $1.5 \mathrm{~cm}$ beyond the end of the last collar pack. Insulation between inner and outer coils and between outer coil and ground is provided by the coil separator and end insulator, respectively.

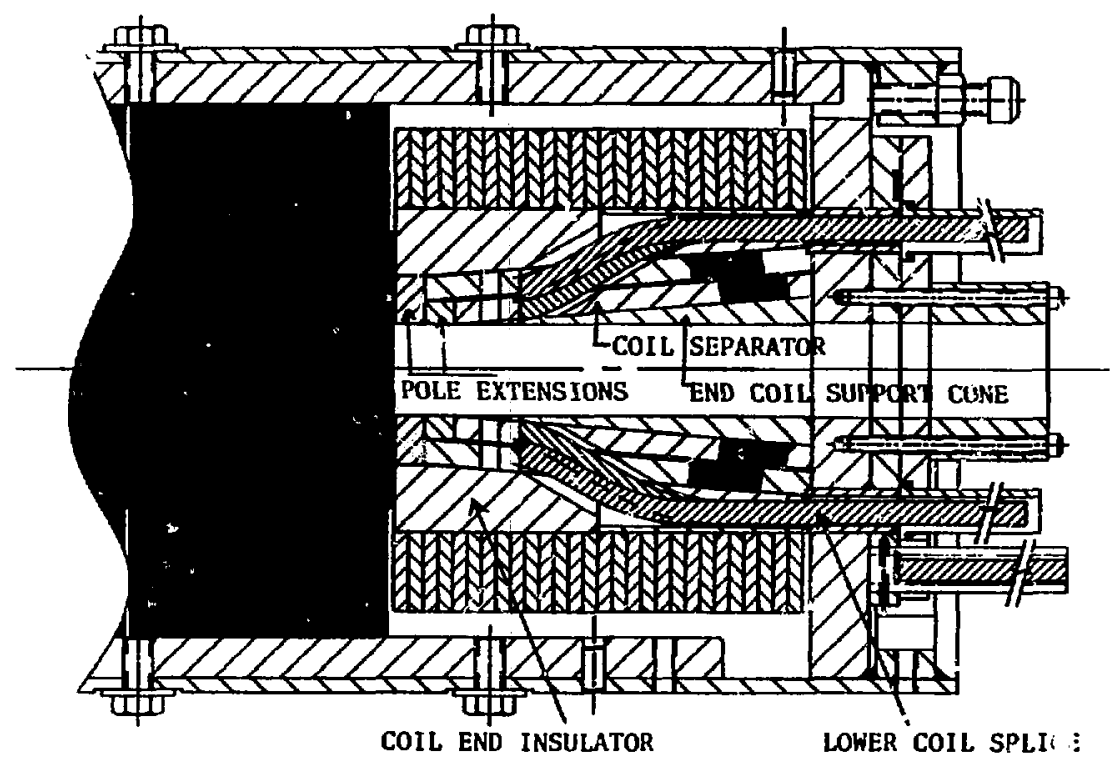

Figure 10 section View of Flared End Magnet

The coil ends in the first model were clamped radially using a bolted S.S. clamp, Figure 11. The azimuthai coil pressure applied to the end at assembly was approximately the same as for the straight collared coil section. Subsequent flared end dipole models will utilize aluminum collars, Figure 10, to clamp the coil ends, rather than the bolted clamps used here. After assembly of yoke and shell, the coil ends are loaded axially to $10,000 \mathrm{lbs}$. by pushing on the coil end sinoes with a $2.5 \mathrm{~cm}$ thick s.s. end plate. End plate loads were monitored during assembly, cooldown, and operation of the magnet. 


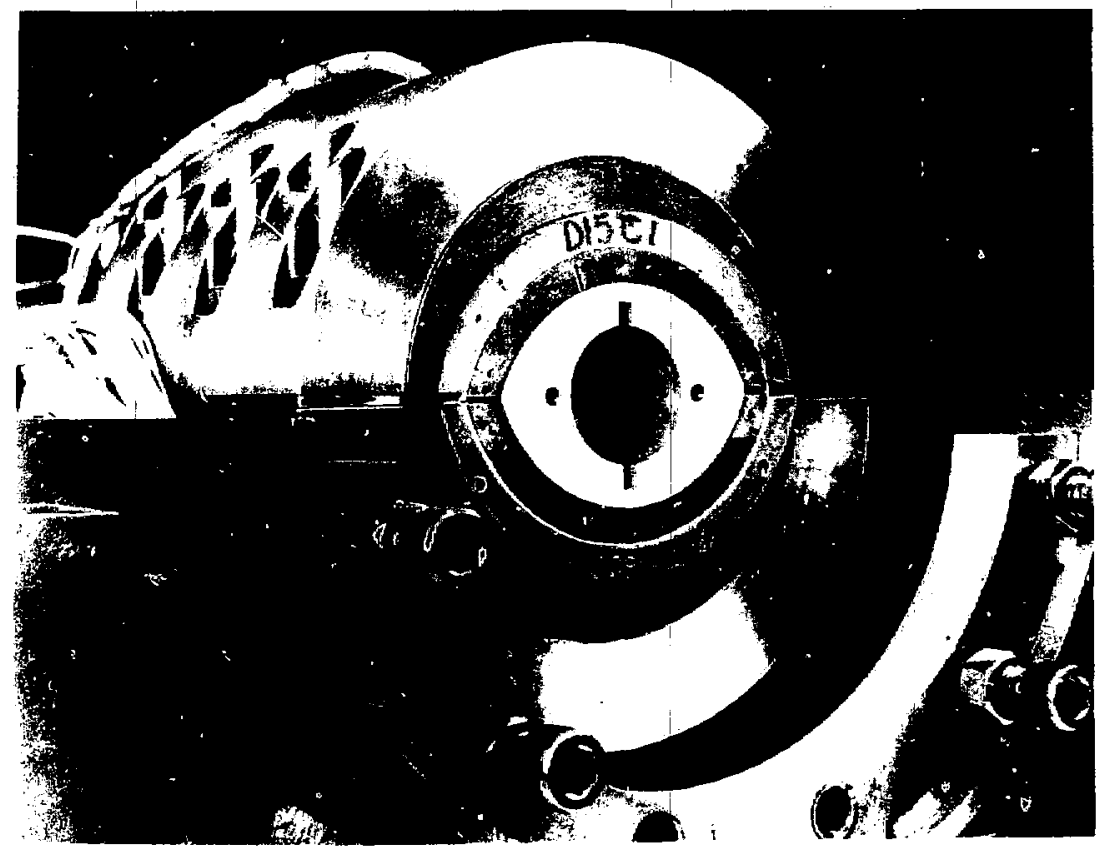

Figure 11 Coil End Clamped Used on First Flared End Model

CBB $891-498$

\section{HARMONIC ANALYSIS}

The concept of harmonic analysis for an "end" is based on a reduction of the 3 dimensional field components to $2 \mathrm{D}$ problem. This is done by integrating the field components with respect to the axial magnet dimension which eliminates the inte rated $\mathrm{z}$ directed field and reduces the problem to an harmonic analysis of integrated 2 dimensional field. Such a detailed analysis was documented in Appendix A (Ref. 1) and the results given as 2 sets of field harmonics one for the straight section and one for the end both having the same fundamental (e.g. the same central dipole field). In this way construction errors resulting in "end harmonics" are totally detached from field errors in the straight section and corrections can therefore be made directly to the "end". Magnetic measurements can also be easily converted into "end harmonics" through a simple transformation. The "end" computations were done on a geometry with no iron and were aimed at providing a geometry with low integrated harmonics. The predicted and measured harmonics are tabulated in Table A, B, and C for the individual layers-inner, outer and both together respectively. (Note that when iron was included, it did not cover the end, but rather terrininate near the end of the straight section). Training behavior at $4.3 \mathrm{~K}$ is excellent and does not appear to be related to coil ends. The magnetic field uniformity of the tapered end is satisfactory for SSC operation. 
Table A

\begin{tabular}{|c|c|c|}
\hline Harmonic & $\begin{array}{c}\text { Predicted } \\
\text { units for a } 12.28 \mathrm{~cm}\end{array}$ & $\begin{array}{c}\text { Measured No Iron } \\
\text { (a 12.03 cm end) }\end{array}$ \\
\hline sextupoie & -89.93 & -80.4 \\
\hline decapole & -17.44 & -21.2 \\
\hline
\end{tabular}

Comparison between computed and measured harmonics for the inner layer only (no iron)

Table B

\begin{tabular}{|c|c|c|}
\hline Harmonic & $\begin{array}{c}\text { Predicted } \\
\text { units for a } 10.41 \mathrm{~cm}\end{array}$ & $\begin{array}{c}\text { Measured No Iron } \\
\text { (a 10.26 cm end) }\end{array}$ \\
\hline sextupole & -101.09 & -92.15 \\
\hline decapole & -9.13 & -7.67 \\
\hline
\end{tabular}

Comparison between computed and measured harmonics for the outer layer only (no iron)

Table C

\begin{tabular}{|c|c|c|c|}
\hline Harmonic & $\begin{array}{c}\text { Predicted } \\
\text { units for a } 11.326 \mathrm{~cm}\end{array}$ & $\begin{array}{c}\text { Measured No Iron } \\
\text { (a } 11.06 \mathrm{~cm} \text { end) }\end{array}$ & $\begin{array}{c}\text { Measured with iron } \\
\text { (a 9.70 cm end) }\end{array}$ \\
\hline sextupoli & 0.001179 & -1.068 & $\mathbf{8 . 0}$ \\
\hline decapole & -13.5327 & -14.94 & -12.35 \\
\hline
\end{tabular}

Comparison between computed and measured harmonics for the two layer dipole.

\section{MAGNET TRAINING}

The initial cryogenic testing took place between February 8 th and 17th, 1989. Memory tests of training were carried out, at $4.3 \mathrm{~K}$, on March 1 st. Figure 12 shows the training history. 
TRAINING OF D-15C-1

LEL-SSC DIPOLE YODEL

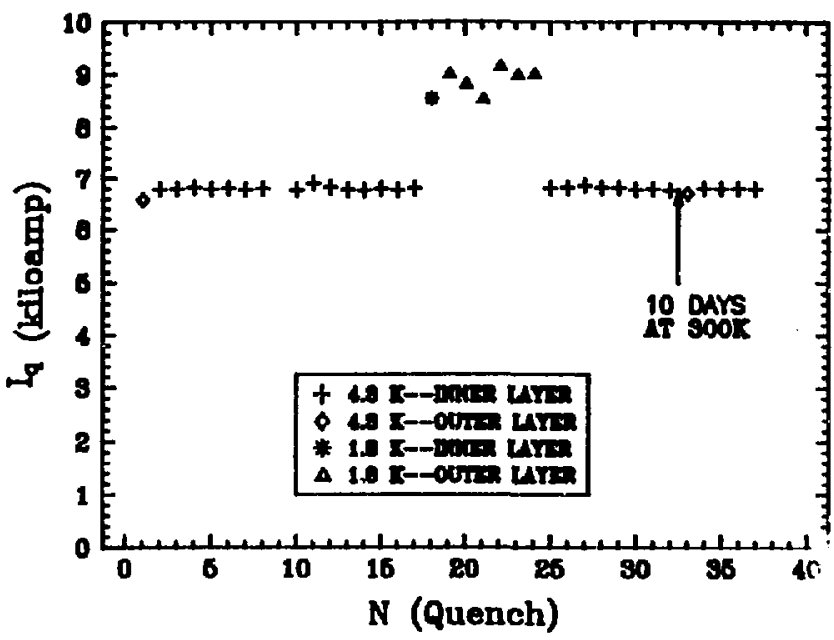

Figure 12 First Flared End Model Training Results

At $4.3 \mathrm{~K}$, the first quench was at $6581 \mathrm{~A}$ in the straight section of the pole turn of the outer layer. The second and all subsequent quenches were in the straight section of the pole turn of the inner layer, at $68 \pm 20 \mathrm{~A}$. This is the same plateau current reached in magnet D15A-3, which has identical superconducting cable in the inner layer. The magnetic field uniformity of the tapered end is satisfactory for SSC operation.

At $1.8 \mathrm{~K}$, the first quench was at $8544 \mathrm{~A}$ in the inner layer, somewhere between tum 4 and turn 16 (midplane), from the pole. The next six quenches were between $8545 \mathrm{~A}$ and $9150 \mathrm{~A}$, but in the outer layer return end, in the pole turn.

After the 10 day thermal cycle, the first retraining quench took place in the return end of the outer layer, but only $1 \%$ below the previous plateau valve. The next four quenches were in the straight section of the pole turn of the inner layer at $(6804 \pm 4) \mathrm{A}$.

\section{CONCLUSION}

The results of the effort develop an alternate coil end design for the SSC Dipole Magnets has been encouraging. The flared end design has proven relatively simple to wind and mold. The larger winding radii have reduced mechanical stresses and insulation trauma and has produced an electrically rugged coil end. The number of individual spacers and insulation pieces required to wind and assemble flared coil ends is fewer than the present straight end coils. The use of CAD for this design enabled accurate computation of geometries for the coils and spacers for prediction of magnetic harmonics and eventual fabrication of the spacers required for the coil ends. The prediction and measurement of coil end magnetic harmonics agreed well and fall within the SSC specification for the ends. 


\section{REFERENCES}

1. S. Caspi and M. Helm, "A "Flared End" Design for the SSC Dipole", June, 17, 1988, SSCMAG-205, LBID-1417. 